\title{
Pyran-Squaraine as Photosensitizers for Dye-Sensitized Solar Cells: DFT/TDDFT Study of the Electronic Structures and Absorption Properties
}

\author{
Reda M. El-Shishtawy, ${ }^{1,2}$ Shaaban A. Elroby, ${ }^{1,3}$ Abdullah M. Asiri, ${ }^{1,4}$ and Rifaat H. Hilal ${ }^{1,5}$ \\ ${ }^{1}$ Chemistry Department, Faculty of Science, King Abdulaziz University, P.O. Box 80203, Jeddah 21589, Saudi Arabia \\ ${ }^{2}$ Dyeing, Printing and Textile Auxiliaries Department, Textile Research Division, National Research Center, Dokki, Cairo 12622, Egypt \\ ${ }^{3}$ Chemistry Department, Faculty of Science, Beni-Suef University, Beni-Suef 6251, Egypt \\ ${ }^{4}$ The Center of Excellence for Advanced Materials Research, King Abdulaziz University, Jeddah 21589, Saudi Arabia \\ ${ }^{5}$ Chemistry Department, Faculty of Science, Cairo University, Cairo, Egypt
}

Correspondence should be addressed to Reda M. El-Shishtawy; elshishtawy@hotmail.com and Shaaban A. Elroby; skamel@kau.edu.sa

Received 27 February 2014; Revised 27 May 2014; Accepted 19 June 2014; Published 1 September 2014

Academic Editor: Juliusz Sworakowski

Copyright (C) 2014 Reda M. El-Shishtawy et al. This is an open access article distributed under the Creative Commons Attribution License, which permits unrestricted use, distribution, and reproduction in any medium, provided the original work is properly cited.

In an effort to provide, assess, and evaluate a theoretical approach which enables designing efficient donor-acceptor dye systems, the electronic structure and optical properties of pyran-squaraine as donor-acceptor dyes used in dye-sensitized solar cells were investigated. Ground state properties have been computed at the B3LYP/6-31+G** level of theory. The long-range corrected density functionals CAM-B3LYP, PBEPBE, PBE1PBE (PBE0), and TPSSH with 6-311++G ${ }^{* *}$ were employed to examine absorption properties of the studied dyes. In an extensive comparison between experimental results and ab initio benchmark calculations, the TPSSH functional with $6-311++\mathrm{G}^{* *}$ basis set was found to be the most appropriate in describing the electronic properties for the studied pyran and squaraine dyes. Natural transition orbitals (NTO), frontier molecular orbitals (FMO), LUMO, HOMO, and energy gaps, of these dyes, have been analyzed to show their effect on the process of electron injection and dye regeneration. Interaction between HOMO and LUMO of pyran and squaraine dyes was investigated to understand the recombination process and charge-transfer process involving these dyes. Additionally, we performed natural bond orbital (NBO) analysis to investigate the role of charge delocalization and hyperconjugative interactions in the stability of the molecule.

\section{Introduction}

Dye-sensitized solar cells (DSSCs) have the potential to compete with conventional silicon solar cells, because of their low-cost of manufacturing, great aesthetic features (color, flexibility, and transparency), and potential for indoor and outdoor implementation. Typical DSSCs are composed of a chromophore that is anchored to a mesostructured, semiconducting $\mathrm{TiO}_{2}$ anode. The improvement of solar energy-to-electricity conversion efficiency has continued to be an important research area of DSSCs [1-11]. The designed dyes that have the structural feature of donor $\pi$-conjugatedacceptor (D-A) system can usually achieve an efficient photovoltaic performance $[12,13]$. The properties of D-A dyes can be easily tuned by varying donor, spacer, and acceptor moieties [14-18]. From this perspective, the dyes play an important role in gaining higher solar-to-electricity conversion efficiency because the performance of DSSCs strongly depends on the following factors which are the criteria for a good dye sensitizer: (1) wide absorption wavelength in visible to near infrared (IR) region to get most of the sunlight; (2) easy electron injection from the excited state of the dyes to the conduction band of $\mathrm{TiO}_{2}$ due to suitable energy levels (HOMO and LUMO), and (3) good electron transfer from the donor to acceptor [19] that would reduce recombination between holes and electrons.

The squaraine class of molecules is well known for its spectroscopic characteristics. The photochemical and 
photophysical properties of these dyes have been studied extensively [20-24] because of their many technological applications in copiers and laser printers [25-27], organic optical disks [28], and organic solar cells. The general structure of symmetric squaraine can be described as a DA-D system, where $\mathrm{D}$ is an electron donor and $\mathrm{A}$ is the central squaric ring, which plays as an electron acceptor. They are characterized by a very strong absorption due to valence $\pi-\pi^{*}$ excitation in the long wavelength region. Motivated by our interest in energy relay dyes for efficient DSSCs and stemmed by our recent results [29], which concluded that the use of 4-(dicyanomethylene)-2-methyl-6(p-dimethylaminostyryl)-4H-pyran (Py) as donor works well with squaraine as acceptor, in this paper, we will attempt to design organic dyes based on Py-squaraine system as donoracceptor in their charge-transfer chromophoric system. The theoretical and experimental studies of pyran dyes have been extensively investigated [30-33]. These dyes are used in many applications such as bulk-heterojunction solar cells, organic light emitting diode (OLED) applications, and sensors [3438]. The chemical structure of these dyes (Scheme 1) consists of a donor moiety (arylamine moiety) and an acceptor moiety (dicyanovinyl moiety) connected by a $\pi$-conjugated structure. The use of the density functional theory (DFT) method for the analysis of the electronic structures and optical properties of organic dyes, which are used for DSSCs, has been reported [39-42]. In the current contribution, the DFT and time-dependent DFT (TDDFT) methods were employed to investigate the molecular geometries, electronic structures, and absorption spectra of suggested prototype D-A-D dyes based on pyran-squaraine molecular systems. Subsequently, the efficiency of DSSCs based on the suggested dyes was evaluated within the following aspects: namely, the light harvesting efficiency (LHE) and the open-circuit voltage $\left(V_{\mathrm{oc}}\right)$ with respect to $\mathrm{TiO}_{2}$ conduction band (CB). The computational results revealed that the extension of $\pi$ conjugation length by adding a benzene ring is helpful for improving the performance of DSSCs. The ultimate goal of the present work, however, is to provide, assess, and evaluate a theoretical approach which enables designing efficient donoracceptor dye systems (Py-squaraine dyes).

\section{Computational Methods}

Ground state equilibrium geometries of the studied Py and squaraine dyes were fully optimized at the DFT level using the B3LYP hybrid functional with the $6-31+G^{* *}$ basis set [43-45]. Frequency calculations were carried out at the same levels of theory in order to characterize the stationary points as local minima. Based upon the optimized geometry, the vertical excitation energies and electronic absorption spectra were calculated using TDDFT $[46,47]$. Five density functionals, namely, the B3LYP, CAM-B3LYP [48], TPSSH [49-52], PBEPBE, and PBE1PBE (PBE0) [53], with 6-311++ ${ }^{* *}$ basis set have been evaluated in order to find out the suitable functional that estimates the absorption behavior of the studied dyes. A possible improvement to get a deeper understanding of the physical nature of the electronic transitions that leans on the representation of an excited state in terms of the NBO

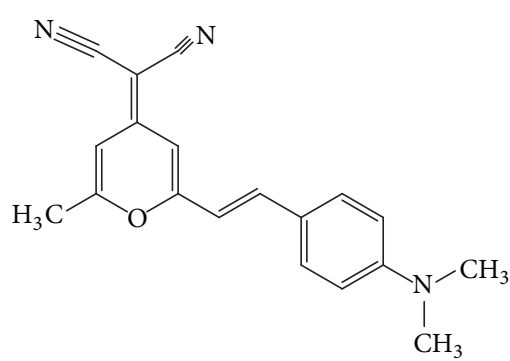

4-(Dicyanomethylene)-2-methyl-6-(p-dimethylaminostyryl)-4H-pyran<smiles>CN(C(=O)O)c1ccc(C2=C([O])C(=C3C=CC(=[N+](C)C)c4cc5ccccc5cc43)C2=O)cc1</smiles>

SQ1

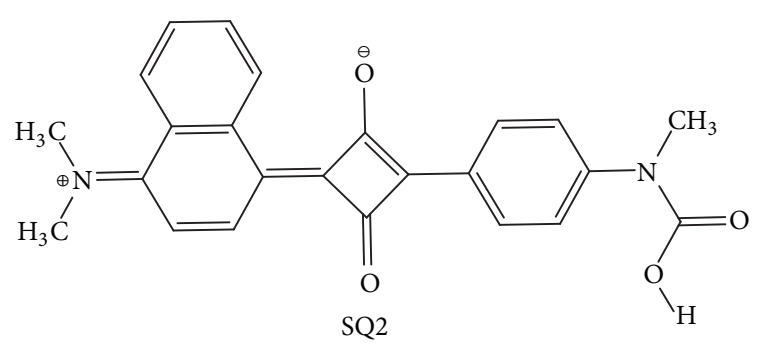

SCHEME 1: The molecular structures of the pyran and squaraine dyes in the present work.

analysis has been carried out to find out various stabilizing interactions in the ground state [54, 55]. All calculations carried out in the present work were performed using the Gaussian09 program package [56].

\section{Results and Discussion}

The chemical structures of the Py and squaraine dyes studied in this work are depicted in Scheme 1. Figure 2 displays the optimized structure parameters of the studied squaraine dyes (SQ1 and SQ2) computed at the B3LYP/6-311++G ${ }^{* *}$ level of theory. Both SQ1 and SQ2 adopt coplanar conformations. This coplanar molecular structure would improve the electron transfer from the electron donor to the electron acceptor through the squaric ring unit for these dyes. There is no effect on the dihedral angles between benzenoid rings and squaric ring in both SQ1 and SQ2. Addition of a third benzenoid ring on the donor part in SQ2 to produce SQ1 does not affect the orientation of the terminal $\mathrm{COOH}$ group. We note a slight decrease of the corresponding bond distances in SQ1 as compared to SQ2. This shortening of bond length is probably due to the presence of the third fused benzene ring which leads to the extension of conjugation and hence more tight binding. Moreover, the length of the bonds between rings 
TABLE 1: Frontier molecular orbitals energies $(\mathrm{eV})$ and energy gap (eV) for studied dyes using TPSSH/6-311++ $\mathrm{G}^{* *}$ level of theory.

\begin{tabular}{|c|c|c|c|c|c|c|}
\hline Compound & HOMO & LUMO & LUMO-HOMO & $V_{\mathrm{oc}}$ & LUMO (SQ)-HOMO (Py) & $V_{\text {oc }}$ \\
\hline SQ1 & -5.34 & -3.26 & 2.02 & 1.72 & 2.05 & 1.75 \\
\hline SQ2 & -5.55 & -3.33 & 2.22 & 1.92 & 1.98 & 1.68 \\
\hline Py & -5.31 & -2.81 & 2.51 & 2.21 & & \\
\hline
\end{tabular}
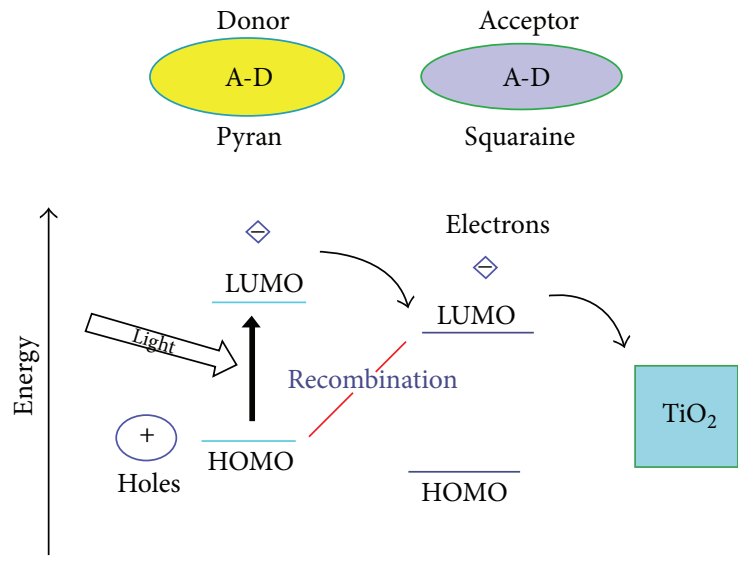

Figure 1: Schematic diagram for a dye-sensitized solar cell in the present study.

and electron-donor groups ranges between 1.38 and $1.43 \AA$ showing especially more double bond character which favors intramolecular charge transfer. In designing D-A-D dyes the $\pi$-conjugated bridge (squaric ring) should be coplanar and therefore the electron can be smoothly injected from the donor moiety to the anchoring group $(\mathrm{COOH})$.

3.1. Intramolecular Charge Transfer (ICT). In designing a dye for DSSCs, there is one main criterion which, involving the FMO's, ought to be carefully considered. The HOMOLUMO energy gap should be small enough to allow high light harvesting capability of the dye but larger than the LUMO$\mathrm{CB}$ separation to allow injection into the $\mathrm{TiO}_{2}$ rather than electron-hole recombination.

The recombination process depends on the energy gap of donor and acceptor dyes $\left(\mathrm{LUMO}_{\mathrm{A}}-\mathrm{HOMO}_{\mathrm{D}}\right)$; see Figure 1. The energies of HOMO, LUMO and energy gap (LUMOHOMO) were collected in Table 1 and Figure 3. The HOMO value of SQ1 is $-5.34 \mathrm{eV}$ which is less than SQ2 by $0.2 \mathrm{eV}$. As shown in Figure 3, LUMO energies of SQ1 and SQ2 are more positive than conduction band $(\mathrm{CB})$ of $\mathrm{TiO}_{2}$. LUMO energy values of SQ1 and SQ2 are -3.26 and $-3.33 \mathrm{eV}$, respectively, as compared to $\mathrm{CB}$ that is $-4.0 \mathrm{eV}$ [57]. Electron injection from LUMO of the excited sensitizers to the conduction band of $\mathrm{TiO}_{2}$ should be energetically favorable because of the more positive LUMO values of the dyes as compared to the $\mathrm{CB}$ energy level of the $\mathrm{TiO}_{2}$. The energy gap between LUMO of acceptor dyes (SQ) and HOMO of donor (Py) is shown in Figure 3. It is indicated that the $E_{g}$ for SQ1 and Py $(2.05 \mathrm{eV})$ is larger than that of SQ2 and Py $(1.98 \mathrm{eV})$. The probability of recombination process in SQ2-Py is, therefore, a little bit higher than that in SQ1-Py.
The maximum open-circuit voltage $\left(V_{\mathrm{oc}}\right)$ of the bulkheterojunction $(\mathrm{BHJ})$ solar cell is related to the difference between the highest occupied molecular orbital (HOMO) of the electron donor and the LUMO of the electron acceptor, taking into account the energy lost during the photocharge generation $[58,59]$. Theoretical values of open-circuit voltage $V_{\text {oc }}$ were calculated from the following expression:

$$
V_{\mathrm{oc}}=E_{\mathrm{LUMO}} \text { (acceptor) }-E_{\mathrm{HOMO}} \text { (Donor) }-0.3 \text {. }
$$

The obtained values of $V_{\text {oc }}$ for the studied molecules calculated according to (1) range from 1.72 to $2.210 \mathrm{eV}$ (Table 1), being sufficient for a possible efficient electron injection.

These results clearly demonstrate that the studied squaraine dyes are potentially efficient for DSSCs especially SQ1. This conclusion is confirmed by electron distribution of natural transition orbitals (NTO) as shown in Figure 4. The electron charge density is distributed mainly on the donor units (squaric ring) before light irradiation but moves to the acceptor units close to the anchoring groups $(\mathrm{COOH})$ after light irradiation; this behavior favors electron injection from dye molecules to the conduction band edge of $\mathrm{TiO}_{2}$. As seen in Figure 4, hole is localized on the center and donor moiety of both squaraine dyes, while the particle shows delocalization throughout the molecules. The electron density moves from donor moiety towards the anchoring group in all transitions in both SQ1 and SQ2 dyes. This feature results in directional electron transfer from such dyes to the conduction band of $\mathrm{TiO}_{2}$. The anchoring group $(\mathrm{COOH})$ in SQ1 and SQ2 has considerable contribution to the LUMOs which could lead to a strong electronic coupling with $\mathrm{TiO}_{2}$ surface and thus improve the electron injection efficiency. This would subsequently enhance the short-circuit current density $J_{\mathrm{sc}}$. In conclusion, the resulting excited states of both dyes are strongly coupled to the $\mathrm{TiO}_{2}$ surface, due to charge delocalization involving the anchoring carboxylic acid group.

3.2. The Electronic Absorption Spectra. In order to have more accurate prediction of the spectral properties of SQ1 and SQ2 dyes, TDDFT computations with the $6-311++\mathrm{G}^{* *}$ basis set were carried out in the gas phase. Benchmark calculations have been performed to assess the best functionals for correctly predicting the absorption spectra of the studied dyes, in particular the low-energy transitions. The excitation energies, oscillator strengths, and contributing configurations for the most relevant first three states of SQ1 and SQ2 dyes using B3LYP, PEBPEB, PEB1PEB (PBE0), CAM-B3LYP, and TPSSH DFT methods with $6-311++\mathrm{G}^{* *}$ basis set are collected in Table 2. The corresponding UV/Vis absorption spectra of these dyes are displayed in Figure 5. 

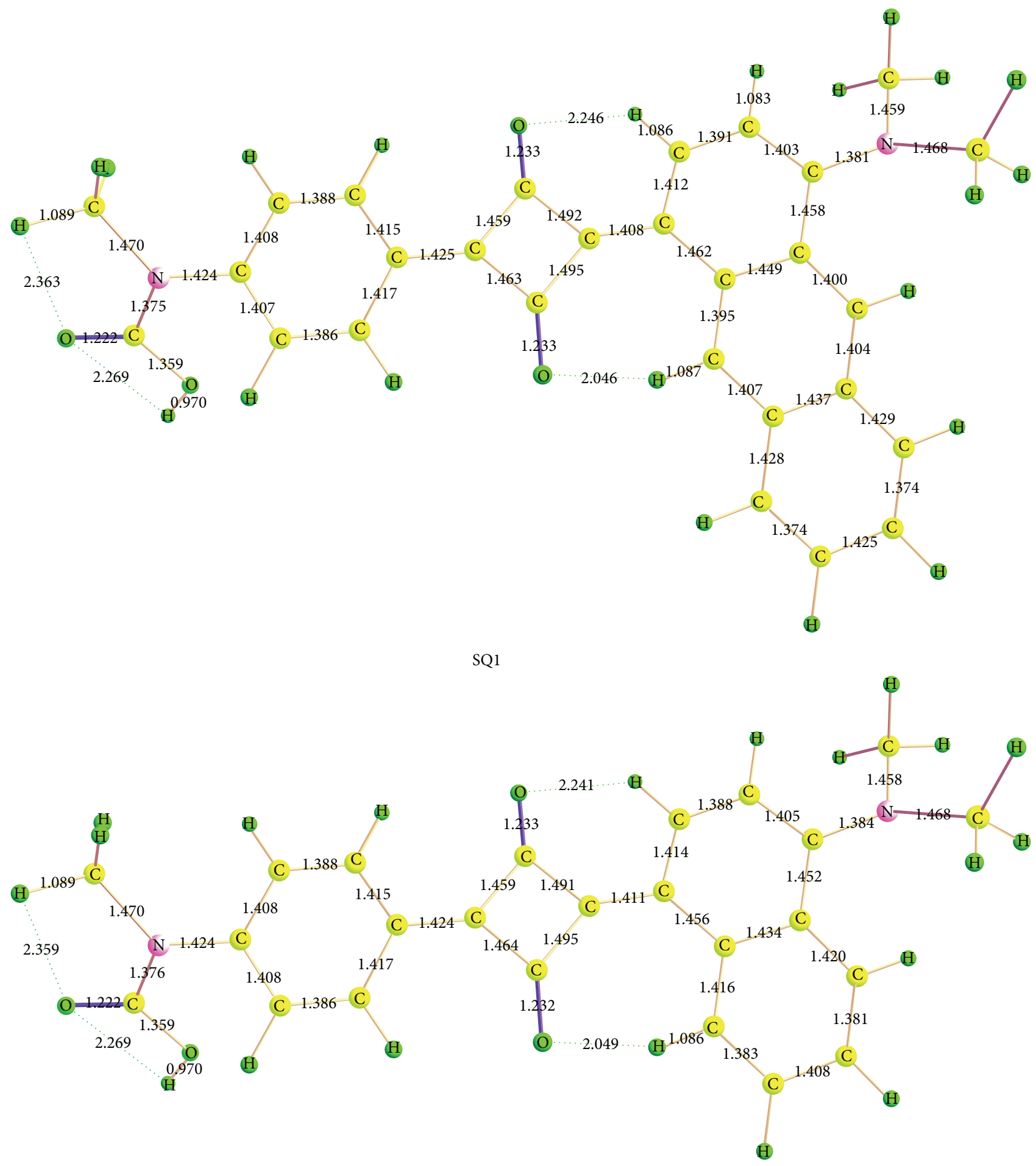

SQ2

FIGURE 2: Optimized geometries for the studied squaraine dyes using B3LYP/6-31+G** level of theory.

Results showed that the wavelength of the peak maximum $\left(\lambda_{\max }\right)$ of ICT spectra is significantly red-shifted in the order PEBPEB $>$ PEB1PEB $>$ TPSSH $>$ B3LYP $>$ CAM-B3LYP. For example, using PEB1PEB, TPSSH, B3LYP, and CAM-B3LYP functionals, $\lambda_{\max }$ values were calculated to be $671.89,625.25$, 608.09, and $566.25 \mathrm{~nm}$, respectively. Comparisons between the calculated and the experimental spectra of a dye of similar structure of SQ1 predicted that $\lambda_{\text {max }}$ obtained from TPSSH calculation is $625.25 \mathrm{~nm}$ which is in excellent agreement with the experimentally observed value of $627.6 \mathrm{~nm}$ [60, 61]. This is in accordance with previous work [29], which indicates that the TPSSH functional is suitable to predict 


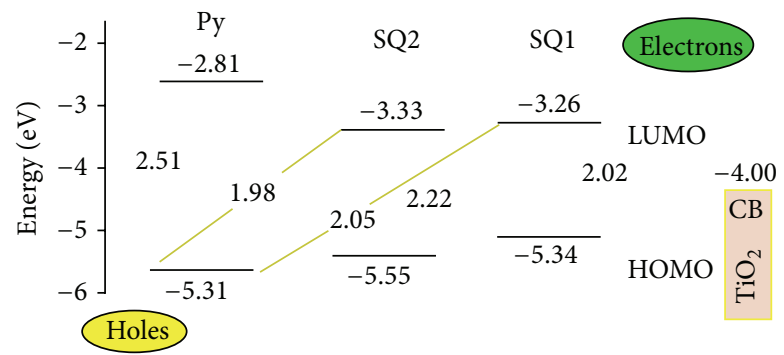

Figure 3: The difference between $E_{\mathrm{HOMO}}$ and $E_{\mathrm{LUMO}}$ for the studied Py, SQ1, and SQ2 dyes at the TPSSH/6-311++G** level of theory.

TABLE 2: Absorption wavelength $(\mathrm{nm})$ and oscillator strength $(f)$ calculated by different functionals using $6-311++\mathrm{G}^{* *}$ basis set for squaraine acceptor dyes.

\begin{tabular}{|c|c|c|c|c|c|c|c|c|}
\hline & \multicolumn{4}{|c|}{ SQ1 } & \multicolumn{4}{|c|}{ SQ2 } \\
\hline & $\begin{array}{l}\text { Wave length } \\
\text { (nm) }\end{array}$ & $f(\mathrm{LHE})$ & $\begin{array}{c}\mathrm{MO} \\
\text { contribution }\end{array}$ & $\begin{array}{c}\text { MO } \\
\text { coefficient }\end{array}$ & $\begin{array}{l}\text { Wave length } \\
\text { (nm) }\end{array}$ & $f$ (LHE) & $\begin{array}{c}\mathrm{MO} \\
\text { contribution }\end{array}$ & $\begin{array}{c}\text { MO } \\
\text { coefficient }\end{array}$ \\
\hline \multirow{5}{*}{ TPSSH } & 738.87 & 0.0016 & $117 \rightarrow 119$ & 0.7037 & 736.86 & 0.0009 & $104 \rightarrow 106$ & 0.704 \\
\hline & 625.25 & $\begin{array}{l}0.8345 \\
(0.853)\end{array}$ & $118 \rightarrow 119$ & 0.687 & 567.26 & $\begin{array}{l}1.1637 \\
(0.931)\end{array}$ & $105 \rightarrow 106$ & 0.709 \\
\hline & 516.08 & 0.1321 & $116 \rightarrow 119$ & 0.654 & 470.82 & 0.0011 & $102 \rightarrow 106$ & 0.677 \\
\hline & & & $118 \rightarrow 119$ & 0.137 & & & & \\
\hline & & & $118 \rightarrow 120$ & 0.214 & & & & \\
\hline \multirow{6}{*}{ B3LYP } & 630.44 & 0.0282 & $117 \rightarrow 119$ & 0.687 & 631.64 & 0.0035 & $104 \rightarrow 106$ & 0.702 \\
\hline & & & $118 \rightarrow 119$ & 0.133 & 557.24 & $\begin{array}{l}1.2116 \\
(0.938)\end{array}$ & $105 \rightarrow 106$ & 0.708 \\
\hline & 608.09 & $\begin{array}{l}0.906 \\
(0.875)\end{array}$ & $118 \rightarrow 119$ & 0.687 & 421.14 & 0.0003 & $101 \rightarrow 106$ & 0.299 \\
\hline & 484.03 & 0.1449 & $116 \rightarrow 119$ & 0.676 & & & $102 \rightarrow 106$ & 0.599 \\
\hline & & & $118 \rightarrow 119$ & 0.106 & & & & \\
\hline & & & $118 \rightarrow 120$ & 0.141 & & & & \\
\hline \multirow{5}{*}{ PEBPBE } & 1036.32 & 0.0004 & $117 \rightarrow 119$ & 0.274 & 1021.87 & 0.0003 & $105 \rightarrow 106$ & 0.703 \\
\hline & & & $118 \rightarrow 119$ & 0.651 & 603.33 & $\begin{array}{l}0.8996 \\
(0.873)\end{array}$ & $102 \rightarrow 106$ & 0.107 \\
\hline & 671.89 & $\begin{array}{l}0.6769 \\
(0.789)\end{array}$ & $114 \rightarrow 119$ & 0.155 & & & $103 \rightarrow 106$ & 0.255 \\
\hline & & & $117 \rightarrow 119$ & 0.609 & & & $104 \rightarrow 106$ & 0.654 \\
\hline & 596.37 & 0.0011 & $115 \rightarrow 119$ & 0.705 & 590.06 & 0.1679 & $103 \rightarrow 106$ & 0.658 \\
\hline \multirow{5}{*}{ CAM-B3LYP } & 566.25 & $\begin{array}{c}1.1978 \\
(0.936)\end{array}$ & $118 \rightarrow 119$ & 0.698 & 535.76 & $\begin{array}{l}1.2807 \\
(0.947)\end{array}$ & $105 \rightarrow 106$ & 0.696 \\
\hline & 498.61 & 0.0016 & $116 \rightarrow 119$ & 0.682 & 503.49 & 0.0084 & $104 \rightarrow 106$ & 0.689 \\
\hline & & & $116 \rightarrow 120$ & 0.139 & 352.1 & 0.0017 & $98 \rightarrow 106$ & 0.652 \\
\hline & 396.76 & 0.0499 & $117 \rightarrow 119$ & 0.657 & & & $103 \rightarrow 106$ & 0.192 \\
\hline & & & $118 \rightarrow 120$ & 0.172 & & & & \\
\hline \multirow{5}{*}{ PEB1PBE } & 599.656 & 0.221 & $117 \rightarrow 119$ & 0.610 & 600.44 & 0.0065 & $104 \rightarrow 106$ & 0.699 \\
\hline & & & $118-119$ & 0.341 & 546.28 & $\begin{array}{l}1.2519 \\
(0.944)\end{array}$ & $105 \rightarrow 106$ & 0.707 \\
\hline & 590.685 & $\begin{array}{c}0.791 \\
(0.838)\end{array}$ & $118-119$ & 0.620 & 402.93 & 0.0003 & $101 \rightarrow 106$ & 0.504 \\
\hline & 461.941 & 0.133 & $116-119$ & 0.682 & & & $102 \rightarrow 106$ & 0.184 \\
\hline & & & $118-120$ & 0.103 & & & & \\
\hline
\end{tabular}

In SQ1, the number of HOMO is 118. In SQ2, the number of HOMO is 105. 

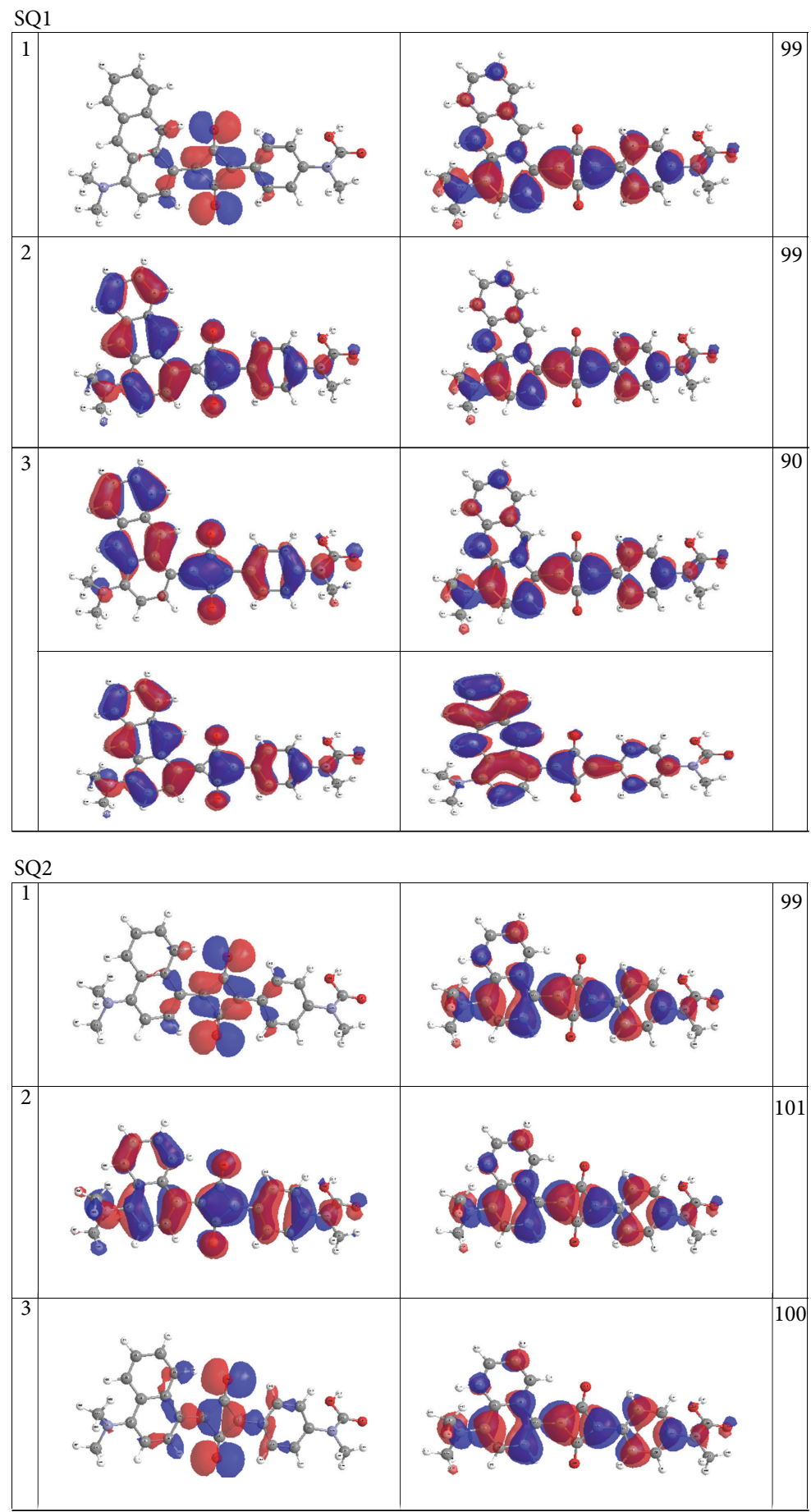

FIGURE 4: Schematic diagram of NTO's of SQ1 and SQ2 calculated at the TPSSH/6-311++ $\mathrm{G}^{* *}$ level of theory. The surfaces are generated with an isovalue at 0.02 .

the electronic structure for Py dye. This study has reported that the calculated $\lambda_{\max }$ value of $457.92 \mathrm{~nm}$ was in excellent agreement with the observed value of $454.0 \mathrm{~nm}$. Furthermore, the calculated absorption wavelengths of SQ1 and SQ2 at TPSSH/6-311++ $\mathrm{G}^{* *}$ level of theory are in good agreement with the corresponding experimental value [58]. This agreement confirms the validity of the TPSSH/6-311++G** level of theory in the prediction of the electronic absorption of squaraine dyes and pyran compounds. Both squaraine dyes show intense narrow absorption bands, but, as a consequence of the extended $\pi$-system of SQ1, their absorption maximum is markedly red-shifted to $625.25 \mathrm{~nm}$ as compared to SQ2 $\left(\lambda_{\max }=567.26 \mathrm{~nm}\right)$. This is true for all DFT methods used in the present work and can be explained, as a consequence of having an extra benzenoid ring in SQ1 and thus more extended conjugation. The absorption spectra of SQ1 show 


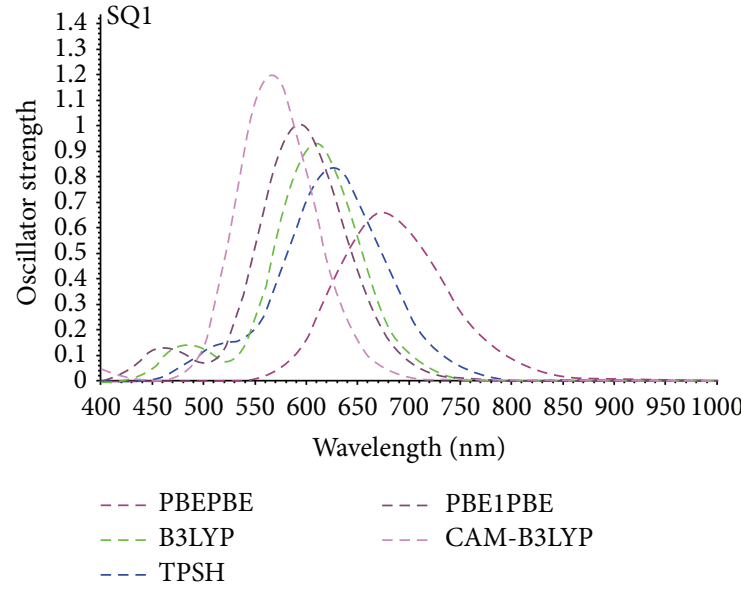

(a)

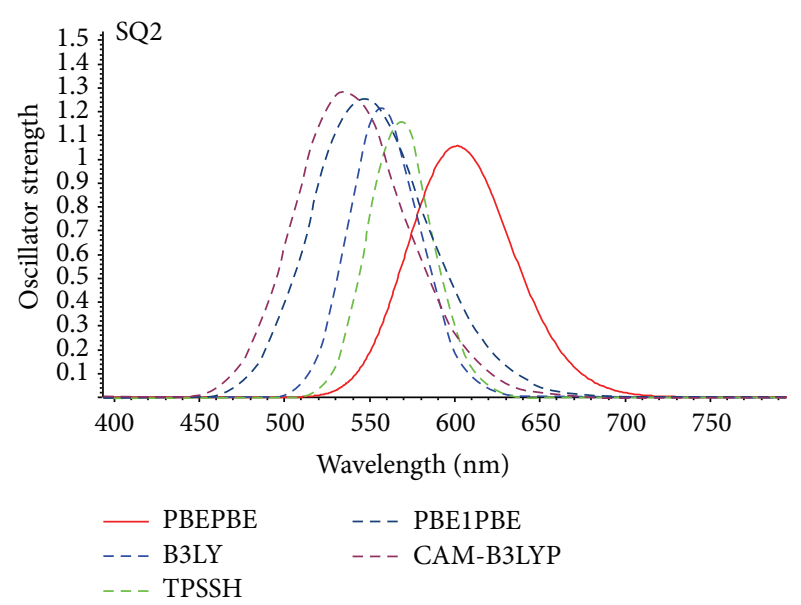

(b)

FIGURE 5: The UV-Vis absorption spectra of SQ1 and SQ2 dyes calculated by different functionals with 6-311++G ${ }^{* *}$ basis set.

a strong optically allowed band at $625.25 \mathrm{~nm}$, corresponding to the HOMO/LUMO transition, and a less intense band at $738.87 \mathrm{~nm}$ roughly corresponding to the HOMO-1 to LUMO transition. On other hand, the TPSSH computed absorption spectra for SQ2 display very strong band at $567.26 \mathrm{~nm}(f=$ $1.164)$ and considerably much less intense band at $736.86 \mathrm{~nm}$ $(f=0.0009)$. The absorption spectra shown in Figure 5 display a red shift in absorption maxima for SQ1 as compared to the corresponding transition in SQ2 irrespective of the DFT functionals used. As seen in Table 2 and Figure 4, the first absorption bands for both SQ1 and SQ2 that are in the near IR region (738.87 $\mathrm{nm}$ and $736.86 \mathrm{~nm}$, resp.) are typical $n-\pi^{*}$ transitions. Furthermore, the third band for both SQ1 and SQ2 that appears at shorter wave length $(516.08 \mathrm{~nm})$ is mainly related to HOMO-2-LUMO transition. Orbital analysis has shown that the transitions are heavily mixed. Hence, NTO analysis has been performed [62]. The NTO orbitals of all transitions computed for SQ1 and SQ2 are included in Figure 4 based on the TD calculation at TSSPH/6-311++ $\mathrm{G}^{* *}$ level of theory. The NTO analysis yields an unambiguous donor-acceptor pair for most cases, thus facilitating the assignment of the nature of the electronic transition. The most prominent transitions in UV-Vis range have been analyzed (Figure 4). It can be clearly seen that $\mathrm{HOMO}$ is localized to a great extent on the squaraine core, which is associated with the $\pi$-framework of the squaric ring. One can notice a similar pattern for the charge density distribution in the NTO of both SQ1 and SQ2. Note that in the excited state there is a clear charge transfer towards the acceptor moiety. In SQ1, there is a further clear accumulation of charge on the anchoring group. This charge accumulation has a pronounced effect in the charge injection into the $\mathrm{CB}$ of the electrode.

TDDFT calculations on SQ1 dye (see Table 2) reveal an intense absorption at $625.25 \mathrm{~nm}(f=0.835)$ associated with the $\pi-\pi^{*}$ electronic transition. This transition corresponds to the excitation from HOMO-LUMO responsible for the facile charge flow from the squaric core to the anchoring group $(\mathrm{COOH})$. As discussed above, in these transitions, the initial states are mainly related to the MOs that are localized on electron-donor groups, while the final states are mainly related to the MOs that are localized on electron acceptor groups. This indicates that the absorptions are photoinduced electron transfer processes; thus the excitations generate charge separated states.

It is instructive at this point to attempt to estimate the light harvesting efficiency (LHE) of the dyes under investigation. LHE can be computed using

$$
\mathrm{LHE}=1-10^{-f},
$$

where $f$ is the computed oscillator strength of the electronic transition. The computed LHE values are listed in Table 2 for the first $\pi-\pi^{*}$ transition for both SQ1 and SQ2. These values suggest that both dyes are promising as photosensitizers with an efficiency ranging from 85 to $95 \%$.

3.3. Natural Bond Orbital Analysis. The second-order perturbation interactions $\left(E^{2}\right)$ between occupied and unoccupied orbitals are used to understand the intramolecular delocalization and donor-acceptor interactions in many systems. In NBO analysis, the delocalization correction to the zerothorder natural Lewis structure, $E^{2}$, is estimated within the second-order energy correction as follows:

$$
E^{2}=q_{i} \frac{F(i, j)^{2}}{\varepsilon_{i}-\varepsilon_{j}},
$$

where $q_{i}$ is the $i$ th donor orbital occupancy, $\varepsilon_{i}$ and $\varepsilon_{j}$ are diagonal elements (orbital energies), and $F(i, j)^{2}$ are offdiagonal elements, associated with the NBO Fock matrix. Therefore, there is a direct relationship between the $F(i, j)$ offdiagonal elements and the orbital overlaps. Results of $\mathrm{NBO}$ analysis of SQ1 and SQ2, for which the values of stabilization energies $E^{2}$ less than $1.0 \mathrm{kcal} / \mathrm{mol}$ are not considered, are summarized in Table 3. 
TABLE 3: Second-order perturbation interactions $\left(E^{2}\right)$ obtained for squaraine dyes at B3LYP/6-311++G** from NBO calculations.

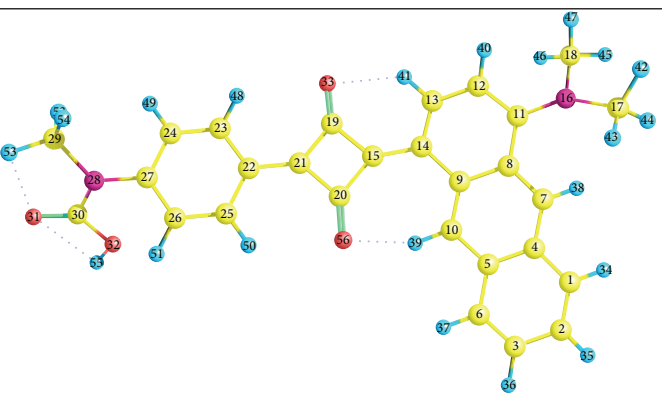

SQ1

\begin{tabular}{l} 
Donor \\
\hline$n_{\mathrm{N} 16}$ \\
$n_{\mathrm{N} 16}$ \\
$n_{\mathrm{O} 33}$ \\
$n_{\mathrm{O} 33}$ \\
$n_{\mathrm{O} 33}$ \\
$n_{\mathrm{O} 56}$ \\
$n_{\mathrm{O} 56}$ \\
$n_{\mathrm{O} 56}$ \\
$n_{\mathrm{O} 56}$ \\
$n_{\mathrm{O} 56}$ \\
$n_{\mathrm{N} 28}$ \\
$n_{\mathrm{N} 28}$
\end{tabular}

Acceptor

$\pi_{\mathrm{C} 8-\mathrm{Cl1}}^{*} 1.49$

$\sigma_{\mathrm{C} 11-\mathrm{C} 12}^{*}$

$\pi_{\mathrm{C} 15-\mathrm{C} 19}^{*}$

$\pi_{\mathrm{C} 15-\mathrm{C} 20}^{*}$

$\pi_{\mathrm{C} 19-\mathrm{C} 21}^{*}$

$\pi_{\mathrm{C} 11-\mathrm{N} 16}^{*}$

$\pi_{\mathrm{C} 15-\mathrm{C} 19}^{*}$

$\sigma_{\mathrm{C} 15-\mathrm{C} 20}^{*}$

$\pi_{\mathrm{C} 20-\mathrm{C} 21}^{*}$

$\pi_{\mathrm{C} 25-\mathrm{C} 26}^{*}$

$\sigma_{\mathrm{C} 29-\mathrm{H} 52}^{*}$
$\pi_{\mathrm{C} 30-\mathrm{O} 31}^{*}$

$\sigma_{\mathrm{C} 11-\mathrm{N} 16}$

$\sigma_{\mathrm{C} 14-\mathrm{C} 15}$

$\pi \pi_{\mathrm{C} 14-\mathrm{C} 15}$

$\pi_{\mathrm{C} 14-\mathrm{C} 15}$

$\sigma_{\mathrm{C} 14-\mathrm{C} 15}$

$\pi_{\mathrm{C} 21-\mathrm{C} 22}$

$\sigma_{\mathrm{C} 27-\mathrm{N} 28}$

$\sigma_{\mathrm{C} 27-\mathrm{N} 28}$

$\sigma_{\mathrm{C} 27-\mathrm{N} 28}$

$\sigma_{\mathrm{C} 27-\mathrm{N} 28}$

$\sigma_{\mathrm{C} 27-\mathrm{N} 28}$

$\sigma^{*}$

$\pi_{\mathrm{C} 15-\mathrm{C} 20}^{*}$

$\pi_{\mathrm{C} 20-\mathrm{C} 21}^{*}$

$\sigma_{\mathrm{C} 21-\mathrm{C} 22}^{*}$

$\pi_{\mathrm{C} 20-\mathrm{C} 21}^{*}$

$\sigma_{\mathrm{C} 13-\mathrm{C} 14}^{*}$

$\sigma_{\mathrm{C} 15-\mathrm{C} 20}^{*}$

$\sigma_{\mathrm{C} 20-\mathrm{C} 21}^{*}$

$\sigma_{\mathrm{C} 21-\mathrm{C} 22}$

$\sigma_{\mathrm{C} 25-\mathrm{C} 26}^{*}$

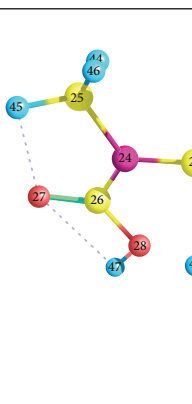

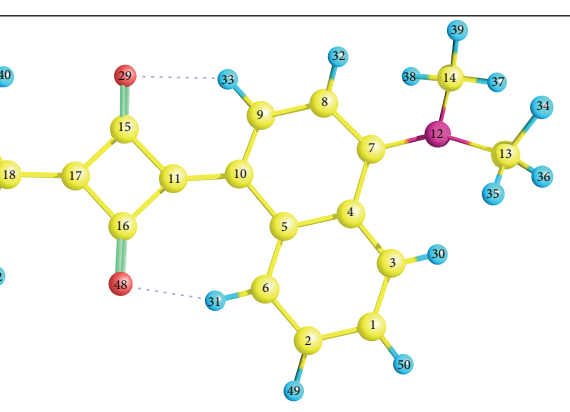

SQ2 
SQ1 increases the conjugated interactions and charge transfer through the molecule.

Another major stabilization interactions have been observed between the p-type lone pair orbital on the two $\mathrm{N}$ atoms and the neighbor $\pi_{\mathrm{C}-\mathrm{C}}^{*}$ antibonding orbitals. The stabilization energy of the two nitrogen lone pairs in the SQ1 and SQ2 is in the $1.0-3.0 \mathrm{kcal} / \mathrm{mol}$ range, which is small as compared to the lone pair stabilization interactions on oxygen atoms. This strong stabilization denotes the larger delocalization for these dyes. The intramolecular hyperconjugative interactions are formed between the terminals and the interdistance bonds with antibonding in the rings which are presented in Table 3. It is evident from this table that the strong intramolecular hyperconjugative interaction of the $\sigma$ and $\pi$ electrons of $\mathrm{C}-\mathrm{C}$ and $\mathrm{C}-\mathrm{N}$ to the anti-C-C bond of the ring leads to stabilization of the molecule. For example, in SQ1, the intramolecular hyperconjugative interaction of $\sigma(\mathrm{C} 27-\mathrm{N} 28)$ distributes to $\sigma^{*}(\mathrm{C} 21-\mathrm{C} 22$ and $\mathrm{C} 15-\mathrm{C} 20)$ that leads to energy stabilization of 26.54 and $15.82 \mathrm{kcal} / \mathrm{mol}$, respectively.

Overall result of the present work highlights the importance of the incorporation of squaraine and benzene rings towards the ground state stabilization of the SQ1 and SQ2 dyes. These results indicated that increasing the conjugated interactions as in SQ1 leads to a reduction in gap energy and shifts the wave length absorption near IR region and thus enhances the efficiency of the photocurrent of SQ1 in DSSC.

\section{Conclusion}

The present study utilizes DFT methods as very effective means that can provide a systematic approach towards the design of efficient solar energy conversion systems such as sensitizers for dye-sensitized solar cells. Thus, the structural, electronic, and optical properties of prototype dyes SQ1, SQ2, and Py were studied at the DFT/TDDFT methods. The three studied dyes have coplanar structure. Results confirm that electrons in SQ1 and SQ2 dyes can be efficiently injected from dyes to $\mathrm{CB}$ of $\mathrm{TiO}_{2}$. Several different DFT functionals have been used in TDDFT calculations to predict the electronic absorption spectra of the studied quatrain dyes. The TDDFT results indicated that TPSSH functional is in much better agreement with experiment. Overall, the present results indicated that the two squaraine dyes (SQ1 and SQ2) exhibit intense and sharp absorption bands in the visible and near infrared regions. These absorption results are in a considerable high light harvesting efficiency (LHE). The intramolecular charge-transfer transitions arising from the "donor-acceptor-donor" arrangements of these dyes have an interesting effect on their excited state properties. The planar structure of SQ1 and SQ2, respectively, in combination with their extended conjugated $\pi$-framework throughout the molecules and their excited state electron distribution involving the carboxylic anchor group allow a highly efficient optical transition. This is reflected in a marked open-circuit voltage $\left(V_{\mathrm{oc}}\right)$ for both SQ1 and SQ2. The squaraine dye SQ1 seems superior in this respect. Furthermore, NBO analysis shed light on the necessary ground state stabilization interactions where $n / \pi^{*}$ and $\pi / \pi^{*}$ interactions are complementing each other in the stabilization. The reduction of the HOMOLUMO energy gap clearly explains the charge-transfer interactions and charge transport process taking place within the studied system. The approach adopted in the present work represents an effective tool for further predictions of new organic dyes.

\section{Conflict of Interests}

The authors declare that there is no conflict of interests regarding the publication of this paper.

\section{Acknowledgments}

This project was funded by the King Abdulaziz City for Science and Technology (KACST) under Grant no. 11-ENE153103. The authors, therefore, acknowledge with thanks KACST for the support for Scientific Research. Also, the authors are appreciating the kind cooperation provided by the Deanship of Scientific Research (DSR), King Abdulaziz University.

\section{References}

[1] S. K. Balasingam, M. Lee, M. G. Kang, and Y. Jun, "Improvement of dye-sensitized solar cells toward the broader light harvesting of the solar spectrum," Chemical Communications, vol. 49, no. 15, pp. 1471-1487, 2013.

[2] H. S. Jung and J. Lee, "Dye sensitized solar cells for economically viable photovoltaic systems," Journal of Physical Chemistry Letters, vol. 4, no. 10, pp. 1682-1693, 2013.

[3] L. Kloo, "On the early development of organic dyes for dyesensitized solar cells," Chemical Communications, vol. 49, no. 59, pp. 6580-6583, 2013.

[4] A. Hagfeldt, G. Boschloo, L. Sun, L. Kloo, and H. Pettersson, "Dye-sensitized solar cells," Chemical Reviews, vol. 110, no. 11, pp. 6595-6663, 2010.

[5] M. K. Nazeeruddin, E. Baranoff, and M. Grätzel, "Dyesensitized solar cells: a brief overview," Solar Energy, vol. 85, no. 6, pp. 1172-1178, 2011.

[6] G. Smestad, C. Bignozzi, and R. Argazzi, "Testing of dye sensitized $\mathrm{TiO}_{2}$ solar cells I: experimental photocurrent output and conversion efficiencies (sol. energy mater. sol. cells 32 (1994) 259-272)," Solar Energy Materials and Solar Cells, vol. 33, no. 2, p. 253, 1994.

[7] M. K. Nazeeruddin, F. De Angelis, S. Fantacci et al., "Combined experimental and DFT-TDDFT computational study of photoelectrochemical cell ruthenium sensitizers," Journal of the American Chemical Society, vol. 127, no. 48, pp. 16835-16847, 2005.

[8] H. Kafafy, H. Wu, M. Peng et al., "Steric and solvent effect in dye-sensitized solar cells utilizing phenothiazine-based dyes," International Journal of Photoenergy, vol. 2014, Article ID 548914, 9 pages, 2014.

[9] Z. Wang, K. Hara, Y. Dan-oh et al., "Photophysical and (photo)electrochemical properties of a coumarin dye," The Journal of Physical Chemistry B, vol. 109, no. 9, pp. 3907-3914, 2005. 
[10] Z. Wang, Y. Cui, K. Hara, Y. Dan-Oh, C. Kasada, and A. Shinpo, "A high-light-harvesting-efficiency coumarin dye for stable dyesensitized solar cells," Advanced Materials, vol. 19, no. 8, pp. 1138-1141, 2007.

[11] R. M. El-Shishtawy, "Functional dyes, and some hi-tech applications," International Journal of Photoenergy, vol. 2009, Article ID 434897, 21 pages, 2009.

[12] Z. Chen, F. Li, and C. Huang, "Organic D- $\pi$-A dyes for dyesensitized solar cell," Current Organic Chemistry, vol. 11, no. 14, pp. 1241-1258, 2007.

[13] M. K. R. Fischer, S. Wenger, M. Wang et al., "D- $\pi$-A sensitizers for dye-sensitized solar cells: linear versus branched oligothiophenes," Chemistry of Materials, vol. 22, no. 5, pp. 1836-1845, 2010.

[14] S.-L. Chen, L.-N. Yang, and Z.-S. Li, "How to design more efficient organic dyes for dye-sensitized solar cells? Adding more sp 2-hybridized nitrogen in the triphenylamine donor," Journal of Power Sources, vol. 223, pp. 86-93, 2013.

[15] J. Feng, Y. Jiao, W. Ma, M. K. Nazeeruddin, M. Grätzel, and S. Meng, "First principles design of dye molecules with ullazine donor for dye sensitized solar cells," Journal of Physical Chemistry C, vol. 117, no. 8, pp. 3772-3778, 2013.

[16] N. Mohammadi, P. J. Mahon, and F. Wang, "Toward rational design of organic dye sensitized solar cells (DSSCs): an application to the TA-St-CA dye," Journal of Molecular Graphics and Modelling, vol. 40, pp. 64-71, 2013.

[17] F. Ambrosio, N. Martsinovich, and A. Troisi, "Effect of the anchoring group on electron injection: theoretical study of phosphonated dyes for dye-sensitized solar cells," Journal of Physical Chemistry C, vol. 116, no. 3, pp. 2622-2629, 2012.

[18] M. Katono, T. Bessho, M. Wielopolski et al., "Influence of the anchoring modes on the electronic and photovoltaic properties of D-A dyes,", Journal of Physical Chemistry C, vol. 116, no. 32, pp. 16876-16884, 2012.

[19] Z. Ning, Y. Fu, and H. Tian, "Improvement of dye-sensitized solar cells: what we know and what we need to know," Energy and Environmental Science, vol. 3, no. 9, pp. 1170-1181, 2010.

[20] K. Y. Law, "Squaraine chemistry. Effects of structural changes on the absorption and multiple fluorescence emission of bis[4-(dimethylamino)phenyl]squaraine and its derivatives," The Journal of Physical Chemistry, vol. 91, no. 20, pp. 5184-5193, 1987.

[21] K.-Y. Law, "Squaraine chemistry. Absorption, fluorescence emission, and photophysics of unsymmetrical squaraines," Journal of Physical Chemistry, vol. 99, no. 24, pp. 9818-9824, 1995.

[22] P. V. Kamat, S. Das, K. G. Thomas, and M. V. George, "Photochemistry of squaraine dyes. 1. Excited singlet, triplet, and redox states of bis[4-(dimethylamino)phenyl]squaraine and bis[4-(dimethylamino)-2-hydroxyphenyl] squaraine," Journal of Physical Chemistry, vol. 96, no. 1, pp. 195-199, 1992.

[23] R. W. Bigelow and H. Freund, "An MNDO and CNDO/ $\mathrm{S}(\mathrm{S}+\mathrm{DES} \mathrm{CI})$ study on the structural and electronic properties of a model squaraine dye and related cyanine," Chemical Physics, vol. 107, no. 2-3, pp. 159-174, 1986.

[24] C. W. Dirk, W. C. Herndon, F. Cervantes-Lee et al., "Squarylium dyes: structural factors pertaining to the negative third-order nonlinear optical response," Journal of the American Chemical Society, vol. 117, no. 8, pp. 2214-2225, 1995.

[25] A. Ajayaghosh, "Chemistry of squaraine-derived materials: near-IR dyes, low band gap systems, and cation sensors," Accounts of Chemical Research, vol. 38, no. 6, pp. 449-459, 2005.
[26] K. Y. Law and F. C. Bailey, "Squaraine chemistry: Effrct of synthesis on the morphological and xerographic properties of photoconductive squaraine," Journal of Imaging Science, vol. 31, no. 4, pp. 172-177, 1987.

[27] P. J. Meiz, R. B. Champ, L. S. Chang et al., "Use of pyrazoline -based carrier transport layers in layered photoconductor systems for electrophotography," Photographic Science, vol. 21, no. 2, pp. 73-78, 1977.

[28] V. P. Jipson and C. R. Jones, "Infrared dyes for optical storage," in Optical Storage Materials, vol. 263 of Proceedings of SPIE, pp. 105-109, 1981.

[29] R. M. El-Shishtawy, A. M. Asiri, S. G. Aziz, and S. A. Elroby, "Molecular design of donor-acceptor dyes for efficient dyesensitized solar cells I: a DFT study," Journal of Molecular Modeling, vol. 20, article 2241, 2014.

[30] M. A. L. Marques and E. K. U. Gross, “Time-dependent density functional theory," Annual Review of Physical Chemistry, vol. 55, pp. 427-455, 2004.

[31] S. G. Awuah, J. Polreis, J. Prakash, Q. Qiao, and Y. You, "New pyran dyes for dye-sensitized solar cells," Journal of Photochemistry and Photobiology A: Chemistry, vol. 224, no. 1, pp. 116-122, 2011.

[32] T. Zhidan, L. Yunchang, T. Baozhu, and Z. Jinlong, "Synthesis and proton-induced fluorescence "OFF-ON" switching of a new $\mathrm{D}-\pi$-A type pyran dye," Research on Chemical Intermediates, 2013.

[33] A. Y. Gerasimenko, V. M. Podgaetsky, V. I. Krasovsky, and A. P. Lugovsky, "Nonlinear absorption in pyran dyes," Optical Memory and Neural Networks (Information Optics), vol. 18, no. 3, pp. 218-222, 2009.

[34] Y. Cui, J. Yu, J. Gao, Z. Wang, and G. Qian, "Synthesis and luminescence behavior of inorganic-organic hybrid materials covalently bound with pyran-containing dyes," Journal of SolGel Science and Technology, vol. 52, no. 3, pp. 362-369, 2009.

[35] J. H. Kim and H. Lee, "Synthesis, electrochemistry, and electroluminescence of novel red-emitting poly(p-phenylenevinylene) derivative with 2-pyran-4-ylidene-malononitrile obtained by the heck reaction," Chemistry of Materials, vol. 14, no. 5, pp. 2270-2275, 2002.

[36] Q. Peng, Z. Y. Lu, Y. Huang et al., "Synthesis and characterization of new red-emitting polyfluorene derivatives containing electron-deficient 2-pyran-4-ylidene-malononitrile moieties," Macromolecules, vol. 37, no. 2, pp. 260-266, 2004.

[37] Y. Son, S. Gwon, S. Lee, and S. Kim, "Synthesis and property of solvatochromic fluorophore based on D-pi-A molecular system: 2-[3-Cyano-4-(N-ethyl-N-(2-hydroxyethyl)amino)styryl]-5,5-dimethylfuran-2(5H)-ylidenemalononitrile dye," Spectrochimica Acta A: Molecular and Biomolecular Spectroscopy, vol. 75, no. 1, pp. 225-229, 2010.

[38] J. L. H. Xue, J. He, X. Gu, Z. Yang, B. Xu, and W. Tian, "Efficient bulk- heterojunction solar cells based on a symmetrical D-piA-pi-D organic dye molecule," Journal of Physical Chemistry C, vol. 113, no. 29, pp. 12911-12917, 2009.

[39] M. P. Balanay and D. H. Kim, "Structures and excitation energies of Zn-tetraarylporphyrin analogues: a theoretical study," Journal of Molecular Structure, vol. 910, no. 1-3, pp. 20-26, 2009.

[40] B. F. Minaev, G. V. Baryshnikov, and A. A. Slepets, "Structure and spectral properties of triphenylamine dye functionalized with 3,4-propylenedioxythiophene," Optics and Spectroscopy, vol. 112, no. 6, pp. 829-835, 2012.

[41] G. V. Baryshnikov, B. F. Minaev, E. V. Myshenko, and A. Minaeva, "Structure and electronic absorption spectra of 
isotruxene dyes for dye-sensitized solar cells: investigation by the DFT, TDDFT, and QTAIM methods," Optics and Spectroscopy, vol. 115, no. 4, pp. 484-490, 2013.

[42] G. V. Baryshnikov, B. F. Minaev, V. A. Minaeva, Z. Ning, and Q. Zhang, "Structure and spectral properties of truxene dye S5," Optics and Spectroscopy, vol. 112, no. 2, pp. 168-174, 2012.

[43] C. Lee, W. Yang, and R. G. Parr, "Development of the ColleSalvetti correlation-energy formula into a functional of the electron density," Physical Review B, vol. 37, no. 2, pp. 785-789, 1988.

[44] A. D. Becke, "Density-functional thermochemistry. III. The role of exact exchange," The Journal of Chemical Physics, vol. 98, no. 7, pp. 5648-5652, 1993.

[45] J. P. Perdew, K. Burke, and Y. Wang, "Generalized gradient approximation for the exchange-correlation hole of a manyelectron system," Physical Review B-Condensed Matter and Materials Physics, vol. 54, no. 23, pp. 16533-16539, 1996.

[46] J. P. Perdew, K. Burke, and M. Ernzerhof, "Generalized gradient approximation made simple," Physical Review Letters, vol. 77, no. 18, pp. 3865-3868, 1996.

[47] M. E. Casida, C. Jamorski, K. C. Casida, and D. R. Salahub, "Molecular excitation energies to high-lying bound states from time-dependent density-functional response theory: characterization and correction of the time-dependent local density approximation ionization threshold," Journal of Chemical Physics, vol. 108, no. 11, pp. 4439-4449, 1998.

[48] R. E. Stratmann, G. E. Scuseria, and M. J. Frisch, "An efficient implementation of time-dependent density-functional theory for the calculation of excitation energies of large molecules," Journal of Chemical Physics, vol. 109, no. 19, pp. 8218-8224, 1998.

[49] D. Jacquemin, V. Wathelet, E. A. Perpète, and C. Adamo, "Extensive TD-DFT benchmark: singlet-excited states of organic molecules," Journal of Chemical Theory and Computation, vol. 5, no. 9, pp. 2420-2435, 2009.

[50] J. P. Perdew, J. Tao, V. N. Staroverov, and G. E. Scuseria, "Metageneralized gradient approximation: explanation of a realistic nonempirical density functional," The Journal of Chemical Physics, vol. 120, no. 15, pp. 6898-6911, 2004.

[51] J. P. Perdew, S. Kurth, A. Zupan, and P. Blaha, "Accurate density functional with correct formal properties: a step beyond the generalized gradient approximation," Physical Review Letters, vol. 82, no. 12, pp. 2544-2547, 1999.

[52] J. Wu, F. Hagelberg, T. C. Dinadayalane, D. Leszczynska, and J. Leszczynski, "Do stone-wales defects alter the magnetic and transport properties of single-walled carbon nanotubes?" Journal of Physical Chemistry C, vol. 115, no. 45, pp. 22232-22241, 2011.

[53] C. Adamo and V. Barone, "Toward reliable density functional methods without adjustable parameters: the PBE0 model," Journal of Chemical Physics, vol. 110, no. 13, pp. 6158-6170, 1999.

[54] A. E. Reed, L. A. Curtiss, and F. Weinhold, "Intermolecular interactions from a natural bond orbital, donor-acceptor viewpoint," Chemical Reviews, vol. 88, no. 6, pp. 899-926, 1988.

[55] F. Biegler-König, J. Schönbohm, and D. Bayles, "IM2000-A program to analyze and visualize atoms in molecules," Journal of Computational Chemistry, vol. 22, no. 5, pp. 545-559, 2001.

[56] M. J. Frisch, G. W. Trucks, H. B. Schlegel et al., Gaussian 03, Gaussian, Inc., Wallingford, Conn, USA, 2009.

[57] S. S. Pandey, R. Watanabe, N. Fujikawa et al., "Effect of extended $\pi$-conjugation on photovoltaic performance of dye sensitized solar cells based on unsymmetrical squaraine dyes," Tetrahedron, vol. 69, no. 12, pp. 2633-2639, 2013.
[58] A. Fitri, A. T. Benjelloun, M. Benzakour et al., "New materials based on thiazolothiazole and thiophene candidates for optoelectronic device applications: theoretical investigations," Research on Chemical Intermediates, vol. 39, no. 6, pp. 26792695, 2013.

[59] W. Li, J. Wang, J. Chen, F.-Q. Bai, and H.-X. Zhang, "Theoretical investigation of triphenylamine -based sensitizers with different p-spacers for DSSC," Spectrochimica Acta Part A, vol. 118, pp. 1144-1151, 2014.

[60] S. Das, K. G. Thomas, P. V. Kamat, and M. V. George, "Photosensitizing properties of squaraine dyes," Journal of Chemical Sciences, vol. 105, no. 6, pp. 513-525, 1993.

[61] P. V. Kamat, S. Das, K. G. Thomas, B. de La Barre, A. Ajayaghosh, and M. V. George, "Photophysics and photochemistry of squaraine dyes. 3. Excited-state properties and poly(4vinylpyridine)-induced fluorescence enhancement of bis $(2,4,6$ trihydroxyphenyl) squaraine," Journal of Physical Chemistry, vol. 96, no. 25, pp. 10327-10330, 1992.

[62] R. L. Martin, "Natural transition orbitals," Journal of Chemical Physics, vol. 118, no. 11, pp. 4775-4777, 2003. 

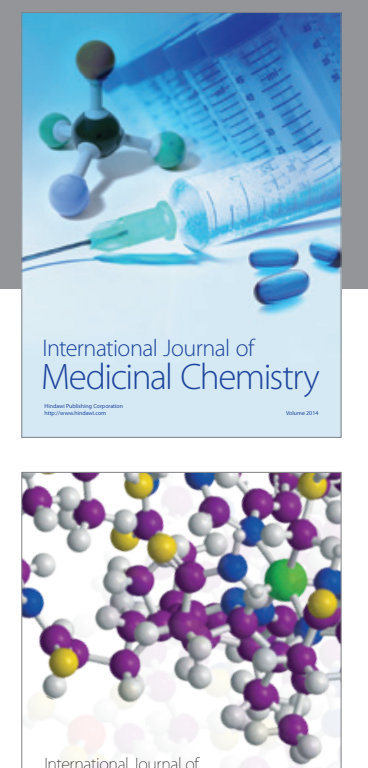

\section{Carbohydrate} Chemistry

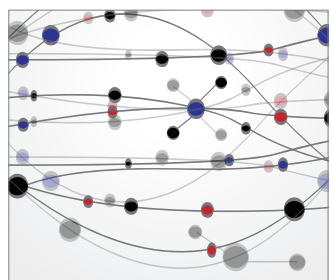

The Scientific World Journal
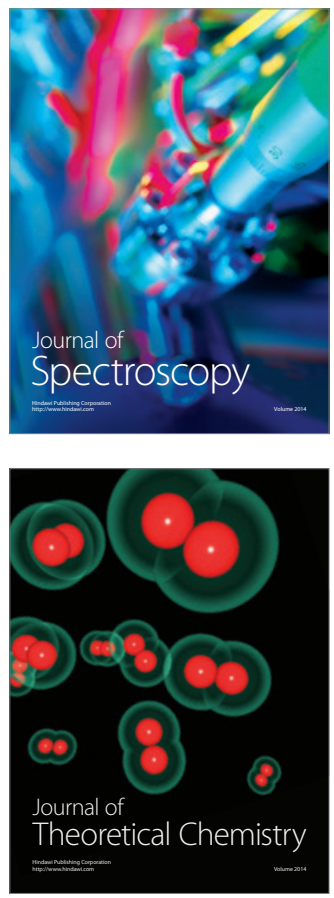
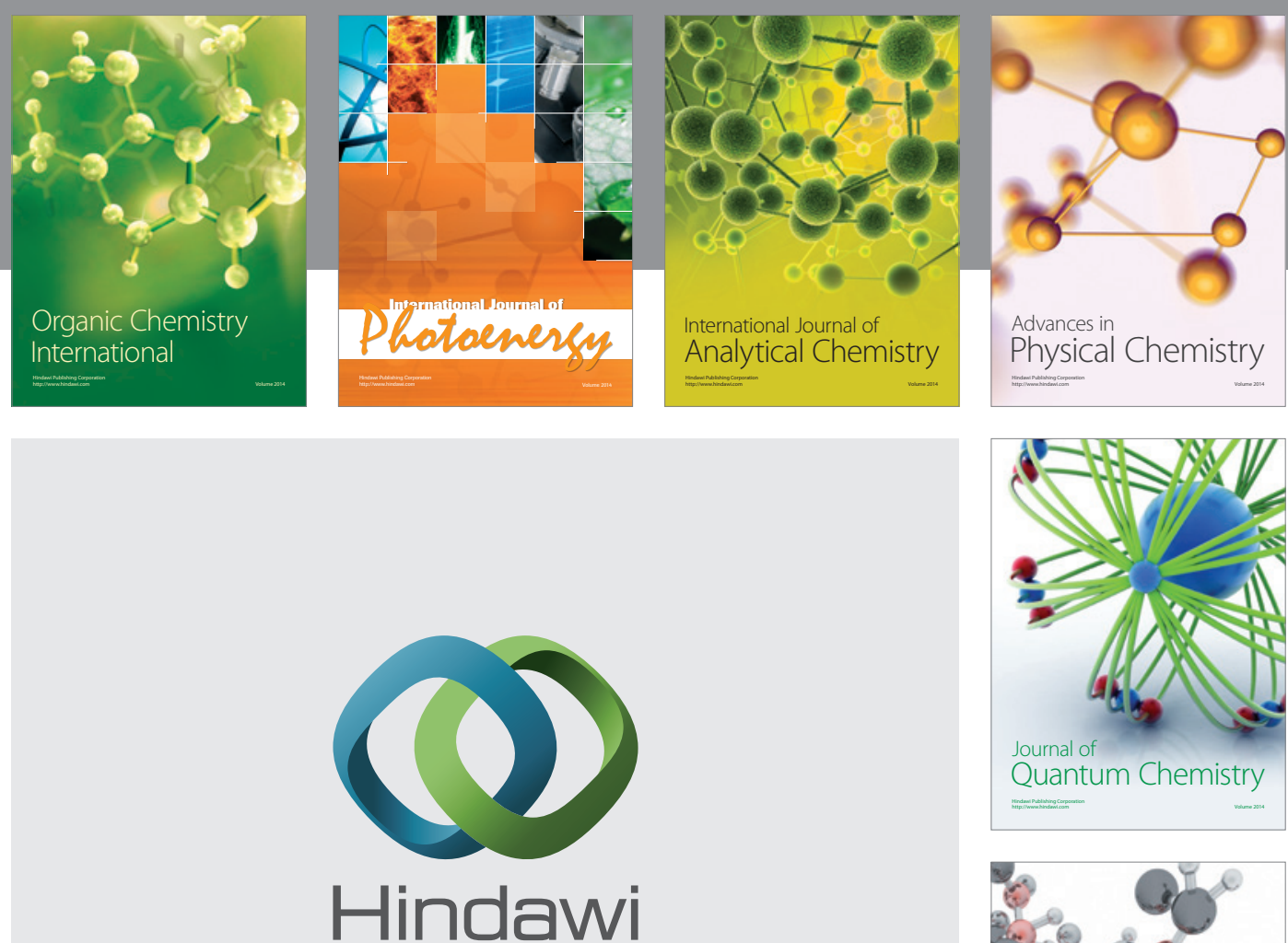

Submit your manuscripts at

http://www.hindawi.com

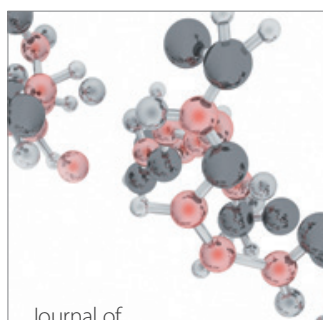

Analytical Methods

in Chemistry

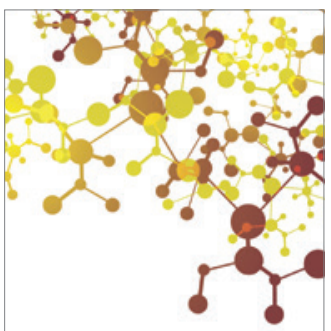

Journal of

Applied Chemistry

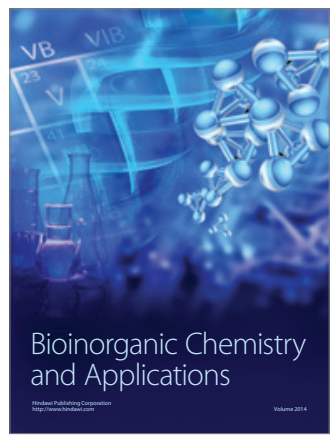

Inorganic Chemistry
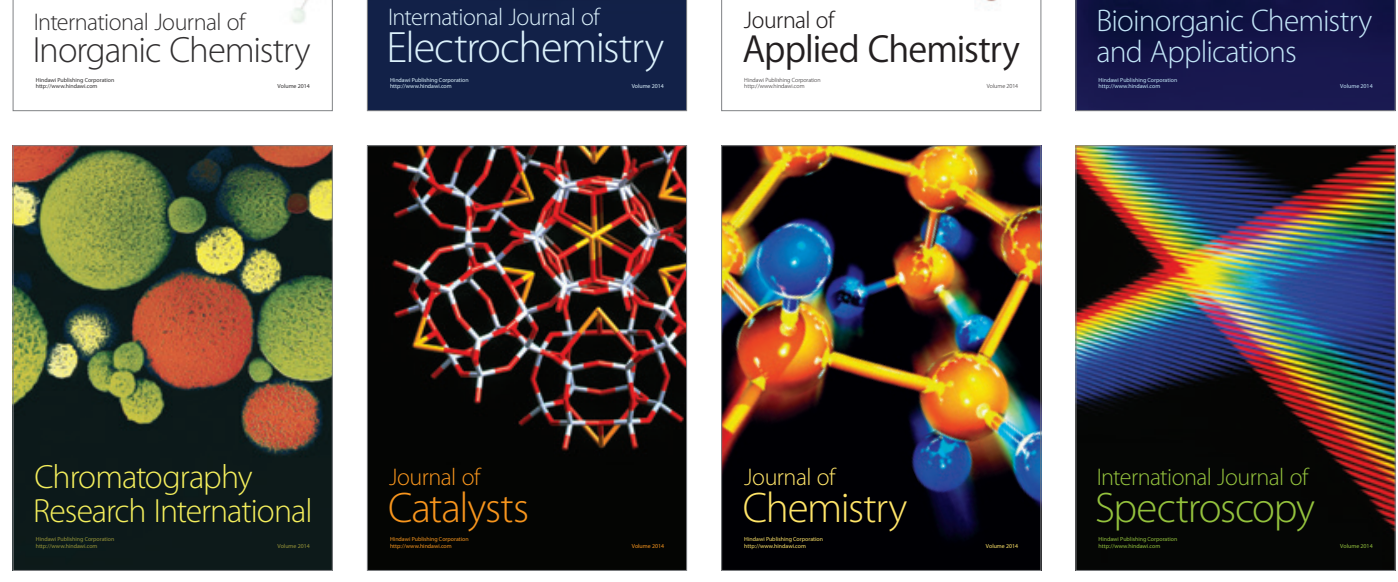